\title{
Low parental support in late adolescence predicts obesity in young adulthood; Gender differences in a 12-year cohort of African Americans
}

Shervin Assari ${ }^{1,2,3^{*}}$, Cleopatra Howard Caldwell ${ }^{2,3}$ and Marc A. Zimmerman 3,4

\begin{abstract}
Background: Most studies that have investigated the link between parenting behaviors and risk of obesity among offsprings have mostly used a cross-sectional design, enrolled Caucasian samples, focused on childhood obesity, and covered aspects of parenting behaviors that directly influence energy balance and food intake of the children. Thus, more longitudinal research is needed on how more general aspects of parenting influence obesity in young ethnic minority adults. The current longitudinal study aimed to test if baseline parental support predicts change in body mass index (BMI) of African Americans, and if this prediction varies based on gender of offspring.

Methods: The current study followed 227 young African American adults (109 male and 118 female) for 12 years from year 2000 (mean age 20) to year 2012 (mean age 32). All participants were enrolled from a disadvantaged urban area in the Midwest of the United States. Baseline demographics (age, gender), socio-economics (family structure, and parental employment), psychological symptoms (anxiety and depression), general parental support (maternal support, and paternal support) were measured. BMI was measured at baseline and at follow up. We used gender-specific linear regressions to test the predictive role of baseline paternal and maternal support (year 2000) on change in BMI (from 2000 to 2012).
\end{abstract}

Results: Regression analysis showed that among female African American young adults, high baseline maternal support was predictive of a lower increase in BMI from 2000 to 2012. The association remained significant while all covariates were in the model. We could not find such an association for male African American young adults.

Conclusion: High maternal support appears to be protective against increases in BMl among African American female young adults. As parental support is a modifiable factor within available evidence-based interventions that enhance parenting, it should be included in obesity prevention programs for African American women. Policies and programs should support African American mothers in disadvantaged neighborhoods to enable them to provide high levels of parental support for their young adult daughters. Future research should test the efficacy of such programs and policies for reducing obesity among African American women.

Keyword: African Americans, Women, Men, Obesity, Parenting, Parental support, Social support

\footnotetext{
* Correspondence: assari@umich.edu

'Department of Psychiatry, School of Medicine, University of Michigan, 4250

Plymouth Rd., Ann Arbor, Ml 48109-2700, USA

${ }^{2}$ Center for Research on Ethnicity, Culture and Health, School of Public

Health, University of Michigan, Ann Arbor, MI, USA

Full list of author information is available at the end of the article
} 


\section{Background}

Although the cross-sectional link between parents' behaviors and offsprings' obesity is known [1-5], it is not known how this association is shaped over time. In addition, although some particular behavior of parents are components of the obesogenic environment for the child [6], it is not clear if more general aspects of parenting also influence risk of obesity of the offspring. Furthermore, it is not clear if this association is independent of confounders such as socio-economic and psychological factors. Finally, less is known about the potential moderating effects of gender for both parent and offspring.

Most studies on the link between parents' behaviors and offspring obesity have focused on specific parenting behaviors that directly impact energy balance (i.e. food consumption, physical activity, and sedentary behavior) [1-5, 7-12]. However, it is not clear if the effects of parents' behaviors on offspring obesity are exclusively limited to the particular parenting behaviors that influence feeding, exercise, nutrition, and sedentary life style [13, 14]. General domains of parenting such as support, closeness, and warmth may also protect the child from the effect of threats that may impose risk for obesity among children [15-19]. In addition poor parenting may directly increase risk of obesity for the child, due to the known effect of chronic stress on the development of obesity [20, 21]. We argue that high quality parenting may have a general protective effect, above and beyond parenting behaviors that directly shape life style and energy balance of the child.

Unfortunately very few studies have measured the effect of general parenting on obesity of offsprings [15-19]. We argue that parental support may be one of the ingredients by which high quality parenting may protect the child against obesity. Hypothetically, supportive parenting may protect the child against exposure and susceptibility to adversity [22]. In this view, parenting support may be particularly protective for children who are living in harsh environments and are commonly exposed to chronic stress, which is known to be obesogenic [23-26].

We use a social support framework [27] to guide the current study. Based on this framework, emotional support has a direct protective effect on health outcomes, and also mitigates the negative effect of stressors [27]. Although residents of disadvantaged areas are exposed to high levels of environmental stress, they may perceive their environment as less stressful if they have access to interpersonal support [28]. This is in line with multiple studies suggesting that offsprings who receive higher levels of parental support report lower levels of perceived stress and psychological distress [28, 29].

Only a handful of studies have ever focused on the influence of parental support on obesity among adults [30, 31]. In 2011, Vámosi et al. enrolled adult same-sexed twin pairs discordant for BMI from the Danish Twin
Registry to test if general parental support was associated with obesity in adults. Their study showed that recalled maternal antipathy and maternal neglect were associated with adult obesity. However, paternal neglect and antipathy were not related to adult obesity [30]. As psychological distress was associated with both parenting and obesity, the results of the study by Vámosi et al., may have been confounded by the psychological status of the participants.

The current longitudinal study was conducted to test if parental support at age 20 was predictive of change in BMI from age 20 to 32 among male and female African American young adults, while the effect of socio-economic status and psychological distress were controlled. We hypothesized that the association between parental support (i.e., mother and father) and change in BMI over time would depend on the gender of the offspring.

\section{Materials and methods}

\section{Design}

Our data came from the Flint Adolescent Study (FAS), a long-term cohort study in Flint Michigan. The study protocol was approved by the University of Michigan Institutional Review Board. All participants signed consent or assent forms before each interview.

Data for the current study came from years 2000 and 2012 when participants were an average age of 20 and 32, respectively. The original study enrolled participants from the ninth grade (age 15) to their transition into adulthood; however, the first measure of body mass index was measured when participants were 21 years old on average.

\section{Participants}

Participants were sampled from four local public high schools. The study enrolled students in the fall semester of ninth grade if they had a grade point average (GPA) of 3.0 or lower in eighth-grade and if they did not have a diagnosis of a developmental disability or emotional impairment. Although the original study included African Americans (80 \%) and Caucasians (17\%), the current study only included African American men and women to focus on an understudied population in BMI research.

\section{Procedure}

Data were collected using structured face-to-face interviews conducted either at school or at alternative community locations. This study followed students who remained in school, as well as those who dropped out of school. Each interview lasted about $60 \mathrm{~min}$ on average.

\section{Covariates}

Baseline age, family structure (i.e., intact vs. not intact family) and family socio-economic status (number of parents who were employed) were used as control variables. 


\section{Maternal support}

Maternal support was measured using a five item modified version of the parental support scale [32]. All items were modified to include "mother" instead of "parent". Using a 5-point Likert scale (1: not true, 5: very true), respondents indicated the extent to which they believed they receive support from their mothers. Areas of support included emotional support, problem solving support, and moral support. Sample items include "I rely on my mother for emotional support" and "My mother is good at helping me solve problems."

\section{Paternal support}

Parental support was measured using a five item modified version of the parental support scale [32]. All questions used the term "father" instead of "parent". Items asked respondents the extent to which they believe they receive support from their fathers. All items used a 5point Likert scale (1: not true, 5: very true). Areas of support included emotional support, problem solving support, and moral support. Sample items include "I rely on my father for emotional support" and "My father is good at helping me solve problems." (Cronbach's alpha = .92 at baseline).

\section{Body mass index}

Body mass index was measured using self-reported weight and height. BMI calculated based on self-reported weight and height is valid and reliable [33, 34]. Several other studies have relied on self-reported weights and heights [35-38]. As weight and height where measured in pounds and inches, respectively, we used the following formula to calculate BMI: BMI $=[$ (weight in pounds $) \div$ (height in inches $\times$ height in inches)] $\times 703$.

\section{Symptoms of anxiety}

Symptoms of anxiety were measured by the Brief Symptom Inventory [39]. Six items assessed the frequency of feeling uncomfortable due to symptoms of anxiety during the past week. Response options were on a Likert scale that ranged from 1 (not at all uncomfortable) to 5 (extremely uncomfortable). Items were averaged to form a scale. This scale has been shown to have high internal consistency and test-retest reliability [40, 41]. (Cronbach's alpha $=.78$ at baseline) .

\section{Symptoms of depression}

Depressive symptoms were measured by six items from the Brief Symptom Inventory [39]. These items assess the frequency of feeling uncomfortable during the past seven days due to symptoms of depression such as feeling hopeless about the future, and having no interest in things. Response options on the Likert scale ranged from 1 (not at all uncomfortable) to 5 (extremely uncomfortable). These six items were averaged to form the final scale. This scale has high internal consistency and test-retest reliability and is valid to use with adolescents [40, 41]. (Cronbach's alpha $=.79$ at baseline).

\section{Data analysis}

We used SPSS 20 (IBM Corp) for data analysis. Descriptive statistics for age, parental support, and BMI were provided using mean and standard deviations (SD). Pearson's correlation was used to measure bivariate associations between the study variables. We fitted multiple linear regressions to test if baseline maternal support (year 2000) predicted change in BMI level from baseline to the end of follow up (year 2012). We did not include paternal support in our multivariable analysis because 113 participants did not know or were not in contact with their fathers. We also ran similar models specific to each young adult's gender to test if these associations varied by gender. In all models, age, number of employed parents, and family structure at baseline were included as controls. P-values less than 0.05 were considered significant. Beta (correlation coefficient) and a $95 \%$ Confidence Interval (CI) were reported.

\section{Results}

\section{Descriptive statistics}

Participants had a mean age of 20 years at baseline. Mean age was 32 at follow up. Baseline symptoms of anxiety, depression, BMI, and change in BMI varied based on gender. All measures listed were higher among females (see Table 1).

\section{Bivariate analysis}

In bivariate analyses, BMI change was not associated with age, parental support, or symptoms of anxiety or depression among males. BMI change was not associated with age, paternal support, or symptoms of anxiety and depression among females. BMI change was, however, associated with maternal support among females (see Table 2).

\section{Regression analysis}

Among females, higher maternal support at baseline predicted lower BMI at follow up. The association remained significant while all covariates were controlled. We could not find such an association among males (see Table 3).

\section{Discussion}

The current study suggests that among female African American adults, low maternal support at age 20 predicts higher BMI increase in the $3^{\text {rd }}$ decade of life. However, a similar association could not be found for males. The association remains significant while socioeconomic status, family structure, anxiety, and depression were controlled. 
Table 1 Descriptive statistics among all, male and females

\begin{tabular}{|c|c|c|c|c|c|c|}
\hline & \multicolumn{2}{|l|}{ Male } & \multicolumn{2}{|l|}{ Female } & \multicolumn{2}{|l|}{ All } \\
\hline & Min-Max & Mean \pm SD & Min-Max & Mean \pm SD & Min-Max & Mean \pm SD \\
\hline Baseline Age & $18.87-21.85$ & $19.94 \pm .66$ & $18.89-21.88$ & $19.79 \pm .62$ & $18.87-21.88$ & $19.86 \pm .65$ \\
\hline Baseline Intact family & $0.00-1.00$ & $.29 \pm .45$ & $0.00-1.00$ & $.21 \pm .41$ & $0.00-1.00$ & $.25 \pm .43$ \\
\hline Baseline Parental employment & $0.00-1.00$ & $.50 \pm .50$ & $0.00-1.00$ & $.45 \pm .50$ & $0.00-1.00$ & $.47 \pm .50$ \\
\hline Baseline Maternal Support & $1.00-5.00$ & $4.11 \pm .94$ & $1.00-5.00$ & $3.96 \pm 1.07$ & $1.00-5.00$ & $4.03 \pm 1.02$ \\
\hline Baseline Paternal Support & $1.00-5.00$ & $3.36 \pm 1.15$ & $1.00-5.00$ & $2.98 \pm 1.24$ & $1.00-5.00$ & $3.14 \pm 1.22$ \\
\hline Baseline Symptoms of Anxiety & $1.00-3.67$ & $1.51 \pm .55$ & $1.00-5.00$ & $1.63 \pm .65$ & $1.00-5.00$ & $1.58 \pm .612$ \\
\hline Baseline Symptoms of Depression & $1.00-4.67$ & $1.64 \pm .64$ & $1.00-5.00$ & $1.83 \pm .76$ & $1.00-5.00$ & $1.75 \pm .71$ \\
\hline Baseline BMI & $15.81-56.48$ & $25.50 \pm 5.43$ & $16.72-54.85$ & $27.14 \pm 7.13$ & $15.81-56.48$ & $26.42 \pm 6.49$ \\
\hline Follow up BMI & $17.93-61.00$ & $29.40 \pm 7.37$ & $17.12-68.63$ & $32.29 \pm 9.42$ & $17.12-68.63$ & $31.09 \pm 8.73$ \\
\hline BMI Gain & $-5.54-23.30$ & $3.94 \pm 4.65$ & $-11.15-25.03$ & $4.19 \pm 5.55$ & $-11.15-25.03$ & $4.10 \pm 5.21$ \\
\hline
\end{tabular}

For at least five reasons, our study is a unique contribution to the literature. First, most of the literature on the association between parenting and offspring obesity is focused on infants and young children, while our study focuses on young adults transitioning into midlife. Second, most previous studies have had an emphasis on parenting styles rather than parental support. Third, most of the literature is composed of cross-sectional studies. Forth, few studies have controlled for psychological health of the offspring. Fifth, less is known about potential gender differences in this regard.

In support of our findings, Barnett et al. [16] followed a nationally representative sample of 37,577 Canadian children and measured parenting styles and children's body mass index (BMI). The study found that compared to authoritarian parenting (setting strict limits, low communication and low affection), authoritative parenting (affectionate, reasonable discussions and set healthy boundaries) may be protective against obesity. The study suggested that authoritative parenting may be associated with a $30 \%$ lower chance of being obese among children
2 to 5 years old and a $37 \%$ lower chance of among children 6 to 11 years. The study suggested that a balance between affection and setting limits may be protective against obesity [16].

The literature on parenting styles with children [42-44] has indicated that authoritative parenting may be associated with low risk for child obesity $[45,46]$. It has been suggested that this effect may be due higher levels of fruit consumption [10] and physical activity [9] among those who have authoritative parents.

A study of Mexican American families showed that indulgent mothers were significantly more likely than authoritative, or authoritarian, mothers to have children who became overweight 3 years later [15]. This finding was in contrast with findings of another study that found that authoritarian parenting style was the best predictor of weight gain in their predominantly middle class, European-American sample [45].

Barlow suggested that interventions should encourage authoritative parenting style in support of increased physical activity and reduced sedentary behavior

Table 2 Correlation matrix of the variables among males and females

\begin{tabular}{|c|c|c|c|c|c|c|c|c|c|c|}
\hline & 1 & 2 & 3 & 4 & 5 & 6 & 7 & 8 & 9 & 10 \\
\hline 1 Baseline Age & 1 & -.099 & -.100 & -.123 & -.055 & .078 & -.007 & .066 & -.062 & -.119 \\
\hline 2 Baseline Intact family & $-.123^{*}$ & 1 & $.146^{* *}$ & $.192^{* *}$ & $.169^{*}$ & -.025 & -.010 & .118 & .084 & -.080 \\
\hline 3 Baseline Parental employment & -.098 & $.128^{*}$ & 1 & .045 & -.004 & -.129 & -.115 & -.055 & .021 & .080 \\
\hline 4 Baseline Maternal Support & .015 & .044 & .016 & 1 & $.361^{* *}$ & $-.236^{* *}$ & $-.290^{* *}$ & -.001 & .097 & .036 \\
\hline 5 Baseline Paternal Support & -.038 & $.163^{*}$ & .091 & $.265^{* *}$ & 1 & -.052 & -.142 & -.033 & .077 & .188 \\
\hline 6 Baseline Anxiety & .043 & -.021 & -.080 & $-.168^{* *}$ & $-.138^{*}$ & 1 & $.689^{* *}$ & -.019 & $-.221^{*}$ & -.148 \\
\hline 7 Baseline Depression & .060 & -.073 & -.087 & $-.294^{* *}$ & $-.279^{* *}$ & $.737^{* *}$ & 1 & .059 & .031 & .008 \\
\hline 8 Baseline BMI & .041 & .024 & -.113 & .021 & -.014 & .019 & -.032 & 1 & $.795^{* *}$ & .177 \\
\hline 9 Follow up BMl & -.002 & -.014 & $-.194^{*}$ & -.075 & .062 & -.002 & -.021 & $.814^{* *}$ & 1 & $.737^{* *}$ \\
\hline 10 BMI Gain & -.127 & -.046 & -.160 & $-.218^{*}$ & -.024 & .055 & .094 & .059 & $.628^{* *}$ & 1 \\
\hline
\end{tabular}

Results above and below diagonal is for males and females, respectively 
Table 3 Summary of regression among the pooled sample, males and females

\begin{tabular}{|c|c|c|c|c|c|}
\hline & \multirow[b]{2}{*}{ Standardized coefficients } & \multirow[b]{2}{*}{ Std. Error } & \multicolumn{2}{|c|}{$95.0 \%$ Confidence interval for B } & \multirow[b]{2}{*}{ Sig. } \\
\hline & & & Lower bound & Upper bound & \\
\hline \multicolumn{6}{|l|}{$\overline{A l l}$} \\
\hline Baseline Age & -.085 & .656 & -2.549 & .038 & .057 \\
\hline Gender & -.009 & .795 & -1.741 & 1.396 & .828 \\
\hline Baseline Intact family & -.057 & .857 & -2.770 & .612 & .210 \\
\hline Baseline Parental employment & -.026 & .600 & -1.538 & .831 & .556 \\
\hline Baseline Maternal Support $^{\mathrm{a}}$ & -.070 & .349 & -1.255 & .122 & .106 \\
\hline Baseline BMI & .813 & .061 & 1.016 & 1.255 & .000 \\
\hline \multicolumn{6}{|l|}{ Men } \\
\hline Baseline Age & -.100 & .931 & -3.062 & .651 & .200 \\
\hline Baseline Intact family & -.126 & 1.224 & -4.392 & .488 & .115 \\
\hline Baseline Parental employment & .028 & .860 & -1.394 & 2.035 & .710 \\
\hline Baseline Maternal Support $^{a}$ & .049 & .548 & -.734 & 1.449 & .516 \\
\hline Baseline BMI & .785 & .108 & .916 & 1.346 & .000 \\
\hline \multicolumn{6}{|l|}{ Women } \\
\hline Baseline Age & -.068 & .913 & -2.921 & .700 & .227 \\
\hline Baseline Intact family & -.030 & 1.192 & -2.988 & 1.739 & .601 \\
\hline Baseline Parental employment & -.055 & .833 & -2.468 & .836 & .330 \\
\hline Baseline Maternal Support ${ }^{\mathrm{a}}$ & -.122 & .458 & -1.943 & -.126 & .026 \\
\hline Baseline BMI & .809 & .076 & .972 & 1.272 & .000 \\
\hline
\end{tabular}

Although bivariate results are reported for paternal support, paternal support is not used in the multivariate analyses due to missing data

(authoritative parents provide both tangible and motivational support for children, and are also demanding and responsive). He argued that interventions should also discourage a restrictive parenting style (restrictive parenting involves heavy monitoring and controlling of a child's behavior) [47].

Our findings extend the results of numerous studies confirming a relation between parenting behaviors and positive child outcomes [44]. Studies differ, however, on the parenting styles associated with the highest obesity risk. A study found that children of authoritarian parents (low nurturance and high control) were at the greatest risk [45]. In contrast, another study found that children of indulgent (high nurturance and low control) and uninvolved (low nurturance and low control) parents showed the greatest risk [46]. Because parents' attitudes toward child rearing are influenced by cultural norms and contextual factors, the effects of different parenting styles often vary across ethnic groups $[48,49]$. Few studies have examined parenting and obesity among minority groups $[15,50]$.

The current study is different from mainstream literature in several ways. Most previous studies in this area have specifically focused on the influence of parents on the food consumption, physical activity, and sedentary behavior of young offspring $[9,10]$. For instance, a study found that for Mexican American mothers, high parental control in feeding was inversely correlated with child
BMI [51], and in two separate studies, Hughes and colleagues found that children of mothers with indulgent feeding styles had the highest BMIs [12, 19].

Parenting behaviors that are closely associated with energy intake control have been shown to be associated with obesity, however, less is known about parenting more broadly defined, including warmth, support, and closeness. There are few studies testing the effect of general parenting on obesity $[15,16]$, and fewer studies have tested the association while other possible confounders are controlled. In brief, studies have suggested that a stressful emotional or neglectful childhood is related to adiposity in childhood and also adulthood, taking into account childhood factors, such as socioeconomic position [31].

Other than feeding, exercise, nutrition, and sedentary life style that are directly associated with obesity, there may be other domains of parenting (such as closeness and support) that may protect the child from the effect of threats that may impose risk of obesity [15-19]. In this view, abusive relation or harsh parenting may act as a stressor and directly increase risk of obesity [21]. The effect of abusive parenting on obesity has been also shown [21,52]. Thus, the protective effect of the parent may not be because of their influence on life style factors that directly influence energy balance, but be because of the protective parental support that has a main or buffering effect against negative effects of stressors [27]. 
In a prospective study of 9310 members of the 1958 British birth cohort who were interviewed at 45 years of age, risk of obesity increased between $20 \%$ and $50 \%$ for adversities such as physical abuse, verbal abuse, witnessed abuse, humiliation, neglect, strict upbringing, physical punishment, conflict or tension, low parental aspirations or interest in education, hardly takes outings with parents, and father hardly reads to child. For most associations, socioeconomic factors partially explained the link between childhood adversity and adulthood obesity [31].

A study by Olvera and Power [15] examined in a lowincome, Mexican American sample, the relations between parenting style and the development of child weight status 3 years later. The study consisted of 80 Mexican American mother-child dyads that participated in a 4-year study [53] and showed links between parenting styles and children's weight status in a 4-year study of low-income, Mexican American families. The results showed that indulgent mothers were significantly more likely than authoritative or authoritarian mothers to have children who became overweight 3 years later [15]. Their findings were in contrast with the findings of another study that found that authoritarian parenting style was the best predictor of weight gain [45]. Although the first study used a minority sample, the second study enrolled a predominantly middle class, European-American sample.

Low socioeconomic status has always been linked to parenting $[54,55]$ and obesity $[56,57]$, thus socioeconomic status may confound the effect of parenting behaviors on obesity of the offspring. It is, not known if the parenting of African Americans that is described as punitive, less consistent, authoritarian, and often including physical discipline [58] is due to their low socioeconomics or not. There are studies suggesting that the differences in parenting by racial groups may be a response to the contextual necessities and opportunities associated with lower socio-economic status [59, 60]. From studies that have disentangled the effects of race from socio-economic status, some suggest it is socioeconomics and education, but not race - per se-, that shape the parenting behaviors of low income African American mothers [61]. Levels of warmth, conflict, and permissiveness that children experience is directly affected by family structure [62].

The study findings are supported by a life course perspective [63-65] which suggests that early exposures in childhood and adolescence influence risk of adult chronic conditions. Adolescence and young adulthood should be considered a sensitive developmental stage, and exposure at this period may shape life course trajectories later in life. In this study, we showed that parental support at age 20 will have long-term health consequences for obesity later in life [65]. These findings are particularly important because obesity of young adults have important implications for developing chronic conditions later in life [63].

The result of this study was specific to African Americans and should be tested for replication among other social groups. Race and culture shape parenting style and behaviors among parents $[66,67]$ and also vulnerability of the offspring to the parenting behaviors [17, 68-71]. Emotional expressivity is influenced by environmental context. Issues such as violent neighborhoods may explain the results of studies that describe the parenting behaviors of African Americans as less warm and less sensitive compared to Caucasians [72]. The parenting style used by African American mothers has been described as positive control where mothers tend to set clear and firm rules and to establish themselves as authority figures [73] in efforts to protect their children. Latino parents have also been characterized as showing high levels of parental control [74-77].

In our study, the negative association between parental support and the development of obesity was limited to female children. Thus, gender of the child changes the vulnerability to the effect of parenting support on obesity [78]. Parents may more frequently employ authoritarian parenting style with boys than with girls [79]. Among African Americans, studies of ethnically diverse families have suggested that African American mothers may use higher levels of negativity and detachment with boys [80]. One study has suggested that maternal but not paternal antipathy and neglect were associated with adult obesity [30].

Olvera and Power provided three possible explanations for why children of low-income minority indulgent mothers may be at highest risk for the development of obesity. First, indulgent mothers may show low levels of control in the feeding context as well; therefore, children may be more frequently exposed to obesogenic foods. Second, children of indulgent parenting may not have the same level of development of self-regulation in eating and exercise $[15,79]$. Finally, indulgent mothers may cater more to their children's unhealthy food preferences or may less frequently encourage children to partake in physical activity [15].

The current findings may have clinical and public health implications for practice. Policy makers may consider policies that support positive parenting among African American women who are living in disadvantaged areas. Family practitioners who work with African American families (particularly single mother families) may design interventions that target enhancement of parenting and parental support as a possible strategy for prevention of obesity among African American women. Family based interventions that enhance parenting may also have implications for obesity prevention among 
African American women. Interventions that enhance positive parenting and improve parental support are available [81-83]. Based on our findings, positive parenting should be also enhanced. The effect of public health programs and policies that enhance parental support among women may have different effects on the obesity of African American female adults than male adults.

Maternal support is a modifiable factor that can be enhanced by interventions. There is well-established literature on programs that effectively enhance parenting [84]. Thus, maternal parenting should be considered as a target for interventions that wish to prevent or reduce obesity among African American women. As there are available interventions that enhance parental support, policy makers, public health programmers and family practitioners may have multiple options to boost parenting support among African American women. Policies are needed to be implemented to enhance parental support among African Americans who are living in disadvantaged neighborhoods.

Future research should replicate our findings in large, diverse samples. Research should also examine the specific mechanisms that account for the relations between parental support and less obesity among minorities [15]. Future research should also explore possible reasons behind gender differences in these areas.

The current findings may help with the prevention of obesity among African American women. In 2011, compared to Caucasians, African Americans were $50 \%$ more likely to be obese, while, the additional risk was $80 \%$ for African American women. This indicates that about four out of five African American women are overweight or obese [20]. In a dose dependent fashion, obesity increases the risk of several cardiovascular outcomes [85]. A paper published in JAMA in 2013 showed that time lived with obesity may also increase the risk of death from cardiovascular causes, independent of BMI [86]. Obesity is known to increase the risk of hypertension [87], diabetes [88], metabolic syndrome [89], cardiovascular disease (CVD) [90], and stroke [91].

The current study is not free of limitations. BMI was based on self-reported weight and height. Our study only used based line measures of family structure, socioeconomic status, and parenting quality, however all these constructs are subject to change. The study also did not include other measures of family socio-economic status such as family income. Despite these limitations, the longitudinal design, long term follow up, a focus on more general aspects of parenting and obesity of young adults, and enrolment of ethnic minorities make the current study a unique contribution to the field.

Our findings are particularly important due to the developmental stage of our participants. Young adults who transition into midlife deal with developmental tasks which are unique to their stage of development. Although they are not as dependent on their mothers for behaviors relevant for obesity like the younger children, maternal support still contributes to their risk of obesity. Thus the effect of parent on obesity of the offspring is beyond childhood and extends to young adults.

To conclude, higher maternal support at age 20 is predictive of less increase in BMI over the 3rd decade of life among African American females but not males. Policies and practices that may enhance maternal support may contribute to prevention of obesity among African American women. Further research should investigate why the effect is not evident for male African American young adults.

\section{Competing interests}

The authors declare that they have no competing interests.

\section{Authors' contributions}

The original idea of this analysis was developed by SA, SA also analyzed the data and drafted the manuscript. MAZ designed the study and acquired the data. MAZ and CHC contributed to all drafts of this manuscript. All authors confirmed the final version of the manuscript. All authors read and approved the final manuscript.

\section{Acknowledgments}

This study was funded by the National Institute on Drug Abuse (NIDA) (grant DA07484) to Marc Zimmerman. The content of this article does not necessarily reflect the views or policies of the National Institute on Drug Abuse. Publication of this manuscript was possible with the support of Department of Psychiatry and also Center for Research on Ethnicity, Culture and Health, University of Michigan to the first author, Shervin Assari.

\section{Author details}

'Department of Psychiatry, School of Medicine, University of Michigan, 4250 Plymouth Rd., Ann Arbor, Ml 48109-2700, USA. ${ }^{2}$ Center for Research on Ethnicity, Culture and Health, School of Public Health, University of Michigan, Ann Arbor, MI, USA. ${ }^{3}$ Department of Health Behavior and Health Education, School of Public Health, University of Michigan, 2846 SPH I, 1415 Washington Heights, Ann Arbor, Ml 48109-2029, USA. ${ }^{4}$ Prevention Research Center, School of Public Health, University of Michigan, Ann Arbor, MI, USA.

Received: 5 December 2014 Accepted: 17 May 2015

Published online: 28 May 2015

\section{References}

1. Johnson SL, Hughes SO, Cui X, Li X, Allison DB, Liu Y, et al. Portion sizes for children are predicted by parental characteristics and the amounts parents serve themselves. Am J Clin Nutr. 2014;99(4):763-70.

2. Frankel LA, O'Connor TM, Chen T, Nicklas T, Power TG, Hughes SO. Parents' perceptions of preschool children's ability to regulate eating: Feeding style differences. Appetite. 2014;76:166-74.

3. Sleddens EFC, O'Connor TM, Watson KB, Hughes SO, Power TG, Thijs CV, et al. Development of the comprehensive general parenting questionnaire for caregivers of 5-13 year olds. Int J Behav Nutr Phys Act. 2014;11:15.

4. Power TG, Sleddens EFC, Berge J, Connell L, Govig B, Hennessy E, et al. Contemporary research on parenting: conceptual, methodological, and translational issues. Childhood Obesity. 2013;9:S87-94.

5. Papaioannou MA, Cross MB, Power TG, Liu Y, Qu H, Shewchuk RM, et al. Feeding style differences in food parenting practices associated with fruit and vegetable intake in children from low-income families. J Nutr Educ Behav. 2013;45:643-51.

6. Gorin AA, Crane MM. The obesogenic environment. In: Jelalian E, Steele R, editors. Handbook of childhood and adolescent obesity. New York: Springer; 2008. p. 145-62.

7. Garstein MA, Young BN, Bridgett D, Panksepp J, Power TG. Origins of effortful control: infant and parent contributions. Infancy. 2013;18:149-83. 
8. Morrison H, Power TG, Nicklas T, Hughes SO. Exploring the effects of maternal eating patterns on maternal feeding and child eating. Appetite. 2013;63:77-83.

9. Schmitz KH, Lytle LA, Phillips GA, Murray DM, Birnbaum AS, Kubik MY. Psychosocial correlates of physical activity and sedentary leisure habits in young adolescents: The Teens Eating for Energy and Nutrition at School Study. Preventive Medicine: An International Journal Devoted to Practice and Theory. 2002;34:266-78.

10. Kremers S, Brug J, de Vries H, Engels R. Parenting style and adolescent fruit consumption. Appetite. 2003;41:43-50.

11. Hughes SO, Patrick H, Power TG, Fisher JO, Anderson CB, Nicklas TA. The impact of child care providers' feeding on children's food consumption. J Dev Behav Pediatr. 2007;28:100-7.

12. Hughes SO, Power TG, Fisher JO, Mueller S, Nicklas TA. Revisiting a neglected construct: parenting styles in a child-feeding context. Appetite. 2005;44:83-92.

13. Burke $V$, Beilin $\sqcup$, Dunbar D. Family lifestyle and parental body mass index as predictors of body mass index in Australian children: a longitudinal study. Int J Obes Relat Metab Disord. 2001;25(2):147-57.

14. Hughes SO, Shewchuk RM, Baskin ML, Nicklas TA, Qu H. Indulgent feeding style and children's weight status in preschool. J Dev Behav Pediatr. 2008;29:403-10.

15. Olvera N, Power TG. Parenting styles and overweight in Mexican-American children: a longitudinal study. J Pediatr Psychol. 2010;35:243-9.

16. Barnett DS T, Paradis G, MD Kakinami I. American Heart Association meeting. 2014. American Heart Association Meeting Report Abstract MP34 http://newsroom.heart.org/news/ruling-with-an-iron-fist-could-make-yourchild-pack-on-pounds?preview $=601 \mathrm{c}$

17. Power TG. Parenting dimensions and styles: a brief history and recommendations for future research. Childhood Obesity. 2013;9:514-21.

18. Frankel LA, Hughes SO, O'Connor TM, Power TG, Fisher JO, Hazen NL. Parental influences on children's self-regulation of energy intake: Insights from developmental literature on emotion regulation. J Obes. 2012;Article ID 327259:12.

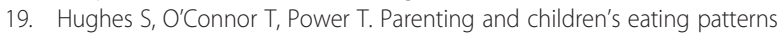
examining parental control in a broader context. International Journal of Child and Adolescent Health. 2008;1:323-30.

20. National Center for Health Statistics. Health, United States, 2012: With Special Feature on Emergency Care. Hyattsville, MD: Library of Congress Catalog Number 76-641496 For sale by Superintendent of Documents U.S. Government Printing Office Washington, DC; 2013. p. 20402.

21. Lissau I, Sørensen TI. Parental neglect during childhood and increased risk of obesity in young adulthood. Lancet. 1994;343(8893):324-7.

22. Parsons TJ, Power C, Logan S, Summerbell CD. Childhood predictors of adult obesity: a systematic review. Int J Obes Relat Metab Disord. 1999;23 Suppl 8:S1-107.

23. Berge JM. A review of familial correlates of child and adolescent obesity: what has the 21st century taught us so far? Int J Adolesc Med Health. 2009;21(4):457-83.

24. Pervanidou P, Chrousos GP. Stress and obesity/metabolic syndrome in childhood and adolescence. Int J Pediatr Obes. 2011;6 Suppl 1:21-8.

25. Pervanidou P, Chrousos GP. Metabolic consequences of stress during childhood and adolescence. Metabolism. 2012;61(5):611-9.

26. Chrousos GP. The role of stress and the hypothalamic-pituitary-adrenal axis in the pathogenesis of the metabolic syndrome: neuro-endocrine and target tissue-related causes. Int J Obes Relat Metab Disord. 2000;24 Suppl 2:S50-5.

27. Cohen S, Wills TA. Stress, social support, and the buffering hypothesis. Psychol Bull. 1985;98(2):310-57.

28. Brenner A, Zimmerman MA, Bauermeister JA, Caldwell CH. Neighborhood context and perceptions of stress over time: an ecological model of neighborhood stressors and intrapersonal and interpersonal resources. Am J Community Psychol. 2013;51:544-56.

29. Carroll JE, Gruenewald TL, Taylor SE, Janicki-Deverts D, Matthews KA, Seeman TE. Childhood abuse, parental warmth, and adult multisystem biological risk in the Coronary Artery Risk Development in Young Adults study. Proc Natl Acad Sci U S A. 2013;110(42):17149-53.

30. Vámosi ME, Heitmann BL, Thinggaard M, Kyvik KO. Parental care in childhood and obesity in adulthood: a study among twins. Obesity (Silver Spring). 2011;19(7):1445-50.

31. Thomas C1, Hyppönen E, Power C. Obesity and type 2 diabetes risk in midadult life: the role of childhood adversity. Pediatrics. 2008;121(5):e1240-9. doi:10.1542/peds.2007-2403.
32. Caldwell CH1, Zimmerman MA, Bernat DH, Sellers RM, Notaro PC. Racial identity, maternal support, and psychological distress among African American adolescents. Child Dev. 2002;73(4):1322-36.

33. Merrill RM, Richardson JS. Validity of self-reported height, weight, and body mass index: findings from the National Health and Nutrition Examination Survey, 2001-2006. Prev Chronic Dis. 2009;6(4):A121. Epub 2009 Sep 15.

34. Ng SP, Korda R, Clements M, Latz I, Bauman A, Bambrick H, et al. Validity of self-reported height and weight and derived body mass index in middleaged and elderly individuals in Australia. Aust N Z J Public Health. 2011;35(6):557-63. doi:10.1111/j.1753-6405.2011.00742.x. Epub 2011 Sep 12.

35. Assari S. Association between obesity and depression among American Blacks: Role of ethnicity and gender. Journal of Racial and Ethnic Health Disparities. 2014;1(1):36-44.

36. Assari $\mathrm{S}$, Caldwell $\mathrm{CH}$. Gender and ethnic differences in the association between obesity and depression among black adolescents. Journal of Racial and Ethnic Health Disparities. 2015;2(1):1-13.

37. Assari S. Additive Effects of Anxiety and Depression on Body Mass Index among Blacks: Role of Ethnicity and Gender. Int Cardiovasc Res J. 2014;8(2):44-51.

38. Assari S, Moghani Lankarani M. The Association between obesity and weight loss intention weaker among blacks and men than whites and women. Journal of Racial and Ethnic Health Disparities 2015: 1-7

39. Derogatis LR, Spencer PM. The Brief Symptom Inventory (BSI): Administration, scoring and procedures manual-I. Baltimore: Johns Hopkins University School of Medicine, Clinical Psychometric Research Unit; 1982.

40. Derogatis LR. The SCL-90: administration, scoring, and procedures manual for the (R)evised version and other instruments of the psychopathology rating scale series. Baltimore: Johns Hopkins University Hospital; 1977.

41. Connolly MB, Crits-Christoph P, Shelton RC, Hollon S, Kurtz J, Barber JP, et al. The reliability and validity of a measure of self-understanding of interpersonal patterns. J Couns Psychol. 1999:46:472-82.

42. Baumrind D. Effects of authoritative control on child behavior. Child Dev. 1966;37:887-907.

43. Baumrind D. Rearing competent children. In: Damon W, editor. Child development today and tomorrow. San Francisco: Jossey-Bass; 1989. p. 349-78.

44. Maccoby EE, Martin J. Socialization in the context of the family: parent-child interaction. In: Mussen PH, Hetherington EM, editors. Handbook of child psychology: Vol. 4. Socialization, personality, and social development. New York: Wiley; 1983.

45. Rhee KE, Lumeng JC, Appugliese DP, Kaciroti N, Bradley RH. Parenting styles and overweight status in first grade. Pediatrics. 2006;117:2047-54.

46. Wake M, Nicholson JM, Hardy P, Smith K. Preschooler obesity and parenting styles of mothers and fathers: Australian National Population Study. Pediatrics. 2007;120:1520-7.

47. Barlow SE. Expert committee recommendations regarding the prevention, assessment, and treatment of child and adolescent overweight and obesity: Summary report. Pediatrics. 2007;120(Suppl4):S164-92.

48. Roche KM, Ensminger ME, Cherlin AJ. Variations in parenting and adolescent outcomes among African American and Latino families living in lowincome, urban areas. J Fam Issues. 2007;28:882-909.

49. Steinberg L, Dornbusch SM, Brown BB. Ethnic differences in adolescent achievement: an ecological perspective. Am Psychol. 1992;47:723-9.

50. Ward CL. Parental perceptions of childhood overweight in the Mexican American population: an integrative review. J Sch Nurs. 2008;24:407-16.

51. Matheson DM, Robinson TN, Varady A, Killen JD. Do Mexican-American mothers' food-related parenting practices influence their children's weight and dietary intake? J Am Diet Assoc. 2006;106:1861-5.

52. Lee $H$, Harris KM, Lee J. Multiple levels of social disadvantage and links to obesity in adolescence and young adulthood. J Sch Health. 2013;83(3):139-49.

53. Hays J, Powers TG, Olvera N. Effects of maternal socialization strategies on children's nutrition knowledge and behavior. J Appl Dev Psychol. 2001;22:421-37.

54. Conger RD, Conger KJ, Martin MJ. Socioeconomic status, family processes, and individual development. J Marriage Fam. 2010;72(3):685-704.

55. Raver CC. Does work pay psychologically as well as economically? The role of employment in predicting depressive symptoms and parenting in low-income families. Child Dev. 2003;74:1720-36.

56. McLaren L. Socioeconomic status and obesity. Epidemiol Rev. 2007;29:29-48.

57. Shrewsbury V1, Wardle J. Socioeconomic status and adiposity in childhood: a systematic review of cross-sectional studies 1990-2005. Obesity (Silver Spring). 2008;16(2):275-84. 
58. McLoyd VC. The impact of economic hardship on Black families and children: psychological distress, parenting, and socioemotional development. Child Dev. 1990;61:311-46.

59. Lareau A. Unequal childhoods: class, race, and family life. Berkeley, CA: University of California Press; 2003.

60. Furstenberg FF, Cook TD, Eccles J, Elder GH, Sameroff AA. Managing to make it: urban families in high risk neighborhoods. Chicago: University of Chicago Press; 1999

61. Middlemiss W. Brief report: poverty, stress, and support: patterns of parenting behavior among lower income black and lower-income white mothers. Infant Child Dev. 2003;12:293-300.

62. Kurdek $L A$, Fine MA. The relation between family structure and young adolescents' appraisals of family climate and parenting behaviour. J Fam Issues. 1993;14:279-90.

63. Kuh D, Ben-Shlomo Y, editors. A life course approach to chronic disease epidemiology. Oxford: Oxford University Press; 1997. p. 101-20.

64. Lumey LH. Reproductive outcomes in women prenatally exposed to undernutrition: a review of findings from the Dutch famine birth cohort. Proc Nutr Soc. 1998;57(1):129-35.

65. Davey Smith G, Hart C, Blane D, Gillis C, Hawthorne V. Lifetime socioeconomic position and mortality: prospective observational study. BMJ. 1997;314:547-52.

66. MacPhee D, Fritz J, Miller-Heyl J. Ethnic variations in personal social networks and parenting. Child Dev. 1996;67:3278-95.

67. Knight GP, Virdin LM, Roosa M. Socialization and family correlates of mental health outcomes among Hispanic and Anglo American children: Consideration of cross-ethnic scalar equivalence. Child Dev. 1994;65:212-24.

68. Mogro-Wilson C. The influence of parental warmth and control on Latino adolescent alcohol use. Hisp J Behav Sci. 2008;30:89-105.

69. Baumrind D. An exploratory study of socialization effects on Black children: Some Black-White comparisons. Child Dev. 1972;43:261-7.

70. Garcia Coll C, Lamberty G, Jenkins R, McAdoo HP, Crnic K, Wasik BH, et al. An integrative model for the study of developmental competencies in minority children. Child Dev. 1996;67:1891-914

71. Ipsa JM, Fine MA, Halgunseth LC, Harper S, Robinson J, Boyce L, et al. Maternal intrusiveness, maternal warmth, and mother-toddler relationship outcomes: Variations across low-income ethnic and acculturation groups. Child Dev. 2004;75:1613-31.

72. Gonzales NA, Hiraga Y, Cauce AM. Observing mother-daughter interaction in African-American and Asian American families. In: McCubbin Hl, Thompson EA, Thompson Al, Futrell JA, editors. Resiliency in African-American families (pp.259-286). Thousand Oaks, CA: Sage; 1998.

73. Varela RE, Vernberg EM, Sanchez-Sosa JJ, Riveros A, Mitchell M, Mashunkashey J. Parenting style of Mexican, Mexican American, and Caucasian-Non-Hispanic families: Social context and cultural influences. J Fam Psychol. 2004;18:651-7.

74. Cardona PG, Nicholson BC, Fox RA. Parenting among Hispanic and AngloAmerican mothers with young children. J Soc Psychol. 2000;140:357-65.

75. Hill NE, Bush KR, Roosa MW. Parenting and family socialization strategies and children's mental health: Low-income Mexican-American and Euro-American mothers and children. Child Dev. 2003;74:189-204.

76. Chao R, Kanatsu A. Beyond socioeconomics: explaining ethnic group differences in parenting through cultural and immigration processes. Appl Dev Sci. 2008;12:181-7.

77. Biblarz TJ, Stacey J. How does the gender of parents matter? J Marriage Fam. 2010;72(1):3-22

78. Dornbusch SM, Ritter PL, Leiderman PH, Roberts DF, Fraleigh MJ. The relation of parenting style to adolescent school performance. Child Dev. 1987;58:1244-57

79. Lengua LJ, Honorado E, Bush NR. Contextual risk and parenting as predictors of effortful control and social competence in preschool children. J Appl Dev Psychol. 2007;28:40-55.

80. Pinderhughes EE, Dodge KA, Bates JE, Pettit GS, Zelli A. Discipline responses: Influences of parent's socioeconomic status, ethnicity, beliefs about parenting, stress, and cognitive-emotional processes. J Fam Psychol. 2000;14:380-400

81. Golley RK1, Hendrie GA, Slater A, Corsini N. Interventions that involve parents to improve children's weight-related nutrition intake and activity patterns - what nutrition and activity targets and behaviour change techniques are associated with intervention effectiveness? Obes Rev. 2011;12(2):114-30.
82. Charles JM, Bywater T, Edwards RT. Parenting interventions: a systematic review of the economic evidence. Child Care Health Dev. 2011;37(4):462-74

83. Wilson S1, McKenzie K, Quayle E, Murray G. A systematic review of interventions to promote social support and parenting skills in parents with an intellectual disability. Child Care Health Dev. 2014;40(1):7-19. doi:10.1111/cch.12023. Epub 2013 Jan 21.

84. Morrison J, Pikhart H, Ruiz M, Goldblatt P. Systematic review of parenting interventions in European countries aiming to reduce social inequalities in children's health and development. BMC Public Health. 2014;14:1040.

85. Klein S, Burke LE, Bray GA, Blair S, Allison DB, Pi-Sunyer X, et al. American Heart Association Council on Nutrition, Physical Activity, and Metabolism. Clinical implications of obesity with specific focus on cardiovascular disease: a statement for professionals from the American Heart Association Council on Nutrition, Physical Activity, and Metabolism: endorsed by the American College of Cardiology Foundation. Circulation. 2004;110(18):2952-67.

86. Reis JP, Loria CM, Lewis CE, Powell-Wiley TM, Wei GS, Carr JJ, et al. Association between duration of overall and abdominal obesity beginning in young adulthood and coronary artery calcification in middle age. JAMA. 2013;310(3):280-8.

87. Landsberg L, Aronne L, Beilin LJ, Burke V, Igel LI, Lloyd-Jones D, et al. Obesity-related hypertension: pathogenesis, cardiovascular risk, and treatment: a position paper of The Obesity Society and the American Society of Hypertension. J Clin Hypertens (Greenwich). 2013;15(1):14-33.

88. Mokdad AH, Ford ES, Bowman BA, Dietz WH, Vinicor F, Bales VS, et al. Prevalence of obesity, diabetes, and obesity-related health risk factors, 2001. JAMA. 2003;289(1):76-9.

89. Ruland S, Hung E, Richardson D, Misra S, Gorelick PB, African American Antiplatelet Stroke Prevention Study Investigators. Impact of obesity and the metabolic syndrome on risk factors in African American stroke survivors: a report from the AAASPS. Arch Neurol. 2005;62(3):386-90.

90. Antillon D, Towfighi A. No time to 'weight': the link between obesity and stroke in women. Womens Health (Lond Engl). 2011;7(4):453-63.

91. Kurth T, Gaziano JM, Berger K, Kase CS, Rexrode KM, Cook NR, et al. Body mass index and the risk of stroke in men. Arch Intern Med. 2002;162(22):2557-62.

\section{Submit your next manuscript to BioMed Central and take full advantage of:}

- Convenient online submission

- Thorough peer review

- No space constraints or color figure charges

- Immediate publication on acceptance

- Inclusion in PubMed, CAS, Scopus and Google Scholar

- Research which is freely available for redistribution 